\title{
Cardiac surgery biochemical monitoring in infants with congenital heart diseases
}

Citation for published version (APA):

Abella Antón, R. F. (2019). Cardiac surgery biochemical monitoring in infants with congenital heart diseases. [Doctoral Thesis, Maastricht University]. ProefschriftMaken Maastricht. https://doi.org/10.26481/dis.20190916ra

Document status and date:

Published: 01/01/2019

DOI:

10.26481/dis.20190916ra

Document Version:

Publisher's PDF, also known as Version of record

\section{Please check the document version of this publication:}

- A submitted manuscript is the version of the article upon submission and before peer-review. There can be important differences between the submitted version and the official published version of record.

People interested in the research are advised to contact the author for the final version of the publication, or visit the DOI to the publisher's website.

- The final author version and the galley proof are versions of the publication after peer review.

- The final published version features the final layout of the paper including the volume, issue and page numbers.

Link to publication

\footnotetext{
General rights rights.

- You may freely distribute the URL identifying the publication in the public portal. please follow below link for the End User Agreement:

www.umlib.nl/taverne-license

Take down policy

If you believe that this document breaches copyright please contact us at:

repository@maastrichtuniversity.nl

providing details and we will investigate your claim.
}

Copyright and moral rights for the publications made accessible in the public portal are retained by the authors and/or other copyright owners and it is a condition of accessing publications that users recognise and abide by the legal requirements associated with these

- Users may download and print one copy of any publication from the public portal for the purpose of private study or research.

- You may not further distribute the material or use it for any profit-making activity or commercial gain

If the publication is distributed under the terms of Article $25 \mathrm{fa}$ of the Dutch Copyright Act, indicated by the "Taverne" license above, 


\section{Chapter 7}

Summary \& conclusion 

There is growing evidence that in last decade the incidence of long-term sequelae and perioperative complications in $\mathrm{CHD}$ infants undergone to $\mathrm{OHS}$ and $\mathrm{CPB}$ has considerably changed. The reasons of these astonishing results reside in the multidisciplinary approach to the disease, involving researchers not only appertaining to the same branch (obstetricians, neonatologists, neuroscientists, cardiologists, cardiac surgeons, biochemists etc.) but experts coming from different disciplines (medical doctor, biologists, molecular biologists, pharmacologists, bio-engineering, informatics, etc.). Nonetheless recent technological advances in prenatal diagnosis and interventions, in perioperative surgery and therapeutic strategies in NICU and PICU provided further effort $[1,2]$. This is especially true for: i) CHD perinatal screening, ii) delivery room management, iii) NICU and PICU admission and preparation to surgery, iv) new cardiac surgery techniques, v) careful $\mathrm{CPB}$ and post-operative management, and finally vi) a future standardized follow-up. Unfortunately, these promising results are, at this stage, still limited to developed countries.

The aforementioned promising results do not let to provide a conclusive answer to the multidisciplinary team questions:

i) which are the CHD cases at high risk for long-term brain injury due to OHS and CPB? ii) Which are the CHD cases at risk for perioperative multiorgan failure?

In light of this, it is widely known that the main issue to solve is $\mathrm{CPB}$ management that today constitutes a deliberate phase of hypoxia-ischemia as the cost to pay during OHS. Another unsolved problem resides in the "so-called" standard monitoring procedures that do not let to the multidisciplinary team to detect at early stage CHD infant's cases at risk for perioperative morbidity and/or mortality.

In the last decades, biochemical longitudinal monitoring of CHD infants in the perioperative period seemed to constitute a new tool able to let the multidisciplinary team reach their goal. In this regard, starting from pioneering research by Westaby et al. in 1996, after twenty years this issue is still controversial and a matter of debate [3]. On one side, previous promising observations in pediatric CHD infants showed that $\mathrm{BM}$ levels changed in $\mathrm{CHD}$ infants, during $\mathrm{OHS}$ and $\mathrm{CPB}$, and correlated with the occurrence of adverse short-long term neurological sequelae [4]. On the other side, the exaggerated releasing of inflammatory cytokines due to HT, DHCA and the rewarming phase showed to affect the availability of some of them thus later abandoned [5-8]. This is especially true for NSE whilst S100B reliability has been recently re-confirmed [5-9]. However, no other trustable BM has been recently proposed and introduced in clinical guidelines [3,4]. Another explanation resides in the studies conducted in terms of design, sample size population, end-points as well as the lack of reference curve agedependent for the majority of the BM investigated. This latter issue has been highlight by recent FDA and EMA statements [10].

In the present thesis, we therefore aimed at providing further support to elucidate the diagnostic/predictive role of AcA and AM in the perioperative period. 
In Chapter 2 we provided an overview of the antenatal and perioperative mechanisms contributing to neurological impairments in critical CHD patients. CNS undergoes major morphological and microstructural changes during fetal life and the neonatal period. Accordingly, critical CHD survivors show primarily a large spectrum of global CNS dysmaturation due to chronic fetal hypoxia. In addition, perioperative hypoxiaischemia due to the CHD and the use of cardiopulmonary bypass or deep hypothermic circulatory arrest provide an additional hit to the neonatal CNS. Consequently, poor neurodevelopment including long-term neurocognitive and motor impairments are prevalent in critical CHD survivors, this despite advances in perioperative and intraoperative care. Innate patient factors, such as genetic syndromes and preterm birth, and postoperative complications play a larger role in neurological injury than perioperative factors. We stated that strategies to reduce the disability burden in critical CHD survivors are urgently needed.

The review provides a framework for interpreting the mechanisms that may help understand the origin of the abnormal antenatal global CNS development and the superimposed perioperative global CNS hypoxia-ischemia in critical CHD.

In Chapter 3 an overview of the main BM (AcA, S100B, G-FAP, NSE, AM, oxidative stress) has been provided, focusing on the potential pros and cons to be overcome before any inclusion in clinical practice in agreement with FDA and EMA criteria [10,11]. At this stage only few BM are closer to being included in daily practice such as AcA and S100B. Conversely, although AM constitutes a potential reliable BM further investigations are needed. If we consider the CHD population the reliability of $\mathrm{BM}$ is still limited to S100B and AcA, but recent Literature data suggested that AM has great potential since it can play both role of vasoactive agent and neuro-marker [11-13].

Additional crucial points reside in the timing and in the reproducibility of the obtained results. The challenge for the multidisciplinary team resides to provide a panel of BM measurable from the same sample, in the shortest time, with the possibility of comparing results independently from different assessment methods, and finally at low costs for sample measurement.

In Chapter 4 we investigated the reliability of AcA in the perioperative period as predictor of short-term adverse neurological outcome. For this purpose, we recruited $45 \mathrm{CHD}$ infants without preexisting neurological disorders who underwent OHS and CPB. Nine out of 45 CHD infants developed neurological injury at 7-d follow-up. AcA was measured in blood samples collected at different monitoring time-points. Results showed that AcA blood levels, significantly increased throughout the perioperative period peaking at the end of CPB. Notably, AcA levels were significantly increased in $\mathrm{CHD}$ infants developing brain injury up to 24 hours from surgery. At cut-off values chosen by the ROC curve analysis (before surgery, $0.94 \mu \mathrm{g} / \mathrm{L}$; before CPB, $1.4 \mu \mathrm{g} / \mathrm{L}$; at the end of $\mathrm{CPB}, 0.85 \mu \mathrm{g} / \mathrm{L})$, AcA reached a sensitivity of $100 \%$ and a specificity of $100 \%$. 
We therefore concluded that peri-operative AcA measurement provides useful information on the early detection of cases at risk for post-surgical neurological stress/ damage.

Results on increased AcA levels in the perioperative period of CHD infant with good neurological outcome warrant further consideration. We are aware that the early increased AcA levels cannot be only expression of a peri-operative stress/damage, although at a sub-clinical stage. Other possibilities need to be explored such as: i) AcA neuro-protection and regenerative actions during and after OHS and CPB procedures. $\mathrm{CPB}$ procedure it-self, constituting the classic HIR event, may trigger the former role. The latter role may be interpreted as an activation of repair processes following $\mathrm{CPB}$, ii) increased AcA due to changes in the brain blood barrier (BBB) permeability following $\mathrm{CPB}$ as for other $\mathrm{BM}$ [5-8]. To our knowledge, no conclusive results have been provided in pediatric patients: the fact that CBP in children affected BBB permeability, in a different modality when compared to adults, has to be taken into the due account (4-8). Thus, the possibility that part of the total amount of the protein detected in the systemic circulation could be BBB-dependent needs to be investigated, and iii) expression of $\mathrm{CHD}$ itself. In this regard, further studies aimed at evaluating AcA differences between cyanotic and non-cyanotic CHD are so justified.

In Chapter 5 we investigated the reliability of AM and MCA Doppler velocimetry parameters in the perioperative period as predictors of adverse neurological outcome at 1-year of age. For this purpose, we recruited $50 \mathrm{CHD}$ infants without preexisting neurological disorders who underwent $\mathrm{OHS}$ and $\mathrm{CPB}$. Ten out $50 \mathrm{CHD}$ infants developed neurological injury at 1-year follow-up. AM was measured in blood samples collected at different monitoring time-points.

Results showed that CHD infants who developed abnormal neurologic outcome had significantly higher MCA values and lower AM concentrations, than infants with normal neurologic outcome, at the end of $\mathrm{CPB}$ and after surgery. As single marker for predicting neurological abnormalities, AM (cut-off value: $17.4 \mathrm{ng} / \mathrm{L}$ ) achieved a sensitivity of $100 \%$ and a specificity of $73.0 \%$, and MCA (cut-off value: $1.8 \mathrm{ng} / \mathrm{L}$ ) a sensitivity of $100 \%$ and a specificity of $56.8 \%$.

We therefore concluded that peri-operative AM measurement provides useful information on the early detection of cases at risk for long-term post-surgical adverse neurological outcome. Of course, further multicenter investigations in a wider population are requested to confirm our observation. Similarly to Chapter 3, results on decreased AM levels in the peri-operative period of CHD infants with good neurological outcome warrant further consideration. Bearing in mind that AM can play both as vasoactive agent and as brain damage marker (acting as a cytokine) we can argue that the decreased AM levels during $\mathrm{CPB}$ cannot be only expression of a peri-operative stress/damage, although at a sub-clinical stage [5-8]. Other possibilities on the AM involvement of pathophysiological mechanisms CPB-related has to be taken into the due account such as: i) AM role in the control of cerebrovascular autoregulation system due to its local action. In this regard, it has been shown that AM release is bloodstream-specific 
(systemic, pulmonary, cerebral, placental etc..) under different pathophysiological conditions such as pulmonary hypertension, fetal acute/chronic hypoxia, neonatal adaptation in the transitional phase (first 72-hours from birth) [5,14-18]. Thus, based on these findings it is tempting to infer that $\mathrm{AM}$ can play a role in $\mathrm{BBB}$ permeability and therefore constitutes a marker of $\mathrm{BBB}$ impairment due to stressing $\mathrm{CPB}$ phases. This issue is supported by previous observations in high risk newborns in whom AM has been shown to be involved in the cascade of HIR events leading to cerebral hemorrhage $[15,16]$; ii) AM release in an oxygen-dependent manner. Literature data reported that under conditions of chronic/acute hypoxia AM release in the systemic circulation, as vasodilation agent, is increased in order to maintain as much as possible the best total body oxygenation $[14,18]$. In the cooling CPB-phase due to low total body temperature the oxygen rate available is dramatically increased as shown at Chapters 3-5. Thus, the lower AM levels can be considered as a compensatory and/or protective mechanism to avoid hyper-oxygenation and consequent free radical over-production. The finding is corroborated by progressive increase in AM levels during the reperfusion (rewarming phase) up to 24-hours from surgery, and iii) AM release as expression of CHD itself. In this regard, further studies aimed at evaluating AM differences between cyanotic and non-cyanotic CHD are so justified.

Finally, In Chapter $\mathbf{6}$ we investigated AM role as predictor of LCOS in the perioperative period. We therefore conducted an observational study in $48 \mathrm{CHD}$ infants of whom 9 were complicated by intra-operative LCOS. The control group was composed of 39 uncomplicated CHD infants. AM was measured in blood samples collected at different monitoring time-points.

Results showed that AM peri-operative concentrations decreased in CHD infants particularly in LCOS group at the end of CPB and of surgical procedure. Multivariable analysis performed to detect the best early predictor of LCOS among a series of standard clinical and laboratory monitoring parameters showed a significant correlation only with AM and cooling phase duration. AM at $27 \mathrm{pg} / \mathrm{L}$ cut-off achieved a sensitivity of $100 \%$ and a specificity of $64.1 \%$ as the best single marker for the prediction of LCOS.

We therefore concluded that AM can constitute a reliable parameter for LCOS prediction and multiorgan failure following LCOS.

The present findings offered additional support to the usefulness of AM longitudinal assessment in the peri-operative period of CHD infants undergone to OHS and CPB. AM pattern of concentration during OHS was superimposable to that detected at Chapter 5, thus supporting the notion of an AM involvement in the cerebral autoregulation system, in BBB permeability and in the vasoactive agent release inhibition due to hyperoxygen blood concentration and temperature (cooling, rewarming) $\mathrm{CPB}$ stress $[5,14-$ 18]. However, before AM inclusion in the peri-operative routine some issues need to be addressed. First, the possibility to measure it at the bed-side providing at the surgical team the results as soon as possible; second, a reliable measurement assay and technique reproducible and at low cost; last but not least, the need of further investigations offering $\mathrm{AM}$ reference curves at the age under investigation. 


\section{References}

1. Karl TR, Jacobs JP. Paediatric cardiac surgical education: which are the important elements? Cardiol Young 2016;26:1465-70.

2. Seghaye MC. Management of children with congenital heart defect: state of the art and future prospects. Future Cardiol 2017;13:65-79.

3. Westaby S, Johnsson P, Parry AJ et al. Serum S100 protein: a potential marker for cerebral events during cardiopulmonary bypass. Ann Thor Surg 1996;61:88-92.

4. Gazzolo D, Abella R, Marinoni E et al. Circulating biochemical markers of brain damage in infants complicated by ischemia reperfusion injury. Cardiovasc Hematol Agents Med Chem. 2009;7:108-26.

5. Vaage J, Anderson R. Biochemical markers of neurologic injury in cardiac surgery: the rise and fall of S100B. J Thorac Cardiovasc Surg 2001;122:853-5.

6. Gazzolo D, Abella R, Frigiola A, et al. Neuromarkers and unconventional biological fluids. J Matern Fetal Neonatal Med 2010;23:66-9.

7. Florio P, Abella R, Marinoni E, et al. Biochemical markers of perinatal brain damage. Front Biosci (Schol Ed) 2010;2:47-72.

8. Gazzolo D, Abella R, Marinoni E, et al. New markers of neonatal neurology. J Matern Fetal Neonatal Med 2009;22:57-61.

9. Caputo M, Mokhtari A, Miceli A, et al. Controlled reoxygenation during cardiopulmonary by-pass decreases markers of organ damage, inflammation and oxidative stress in single-ventricle patients undergoing pediatric heart surgery. J Thorac Cardiovasc Surg 2014;148:792-801.

10. Serpero LD, Bellissima V, Colivicchi M et al. Next generation biomarkers for brain injury. J Matern Fetal Neonatal Med. 2013;26:44-9.

11. Graham EM, Everett AD, Delpech JC et al. Blood biomarkers for evaluation of perinatal encephalopathy: state of the art. Curr Opin Pediatr 2018;30:199-203.

12. Hauser JA, Demyanets S, Rusai K et al. Diagnostic performance and reference values of novel biomarkers of paediatric heart failure. Heart 2016;102:1633-9.

13. Zhang S, Patel A, Moorthy B et al. Adrenomedullin deficiency potentiates hyperoxic injury in fetal human pulmonary microvascular endothelial cells. Biochem Biophys Res Commun 2015;464:10481053.

14. Caputo M, Mokhtari A, Miceli A, et al. Controlled reoxygenation during cardiopulmonary by-pass decreases markers of organ damage, inflammation and oxidative stress in single-ventricle patients undergoing pediatric heart surgery. J Thorac Cardiovasc Surg 2014;148:792-801. 
15. Di Iorio R, Marinoni E, Letizia C, et al. Adrenomedullin is increased in the fetoplacental circulation in intrauterine growth restriction with abnormal umbilical artery waveforms. Am J Obstet Gynecol 2000;182:650-4.

16. Di Iorio R, Marinoni E, Gazzolo D, et al. Maternal nitric oxide supplementation increases adrenomedullin concentrations in growth retarded fetuses. Gynecol Endocrinol 2002;16:187-92.

17. Gazzolo D, Marinoni E, Giovannini L, et al. Circulating adrenomedullin is increased in preterm newborns developing intraventricular hemorrhage. Pediatr Res 2001;50:544-7.

18. Di Iorio R, Marinoni E, Lituania M, et al. Adrenomedullin increases in term asphyxiated newborns developing intraventricular hemorrhage. Clin Biochem 2004;37:1112-6. 